\title{
INHIBITORY EFFECT OF ASCORBIC ACID MICROEMULSION ON PHOTO-OXIDIZED VIRGIN COCONUT OIL
}

\begin{abstract}
Ambar Rukmini ${ }^{1}$
ABSTRACT

The effect of water-in-oil (w/o) microemulsion containing ascorbic acid on photo-oxidative stability of virgin coconut oil (VCO) was investigated. To optimize the formulation, w/o microemulsions were prepared using hydrophilic lipophilic balance (HLB) concept, consisted of ternary nonionic surfactants having low, medium, and high HLB values. From this optimum HLB number, the ratio of water, surfactant and oil was determined to obtain microemulsion areas. After optimization of the microemulsion system, the storage at room temperature, and the extreme condition were conducted for testing the microemulsion stability. Then, the stable formulas were used for delivering ascorbic acid. The solubility and photo-oxidative stability of ascorbic acid microemulsion were evaluated. The optimum formula of ascorbic acid microemulsion was applied into VCO at various concentrations $(0,1,5$, and 10\% w/w). Samples were subjected to photo-oxidation under fluorescent light exposure of 4000 lux for up to 8 hours. Peroxide values (PVs) and $p$-anisidine values $(p-A n V s)$ of the samples were measured at 1 hour interval. The results indicated that w/o microemulsion could be formed on the HLB number of 7 . W/o microemulsion containing $75 \%$ oils need surfactant concentrations of $\geq 4.5$ part of water, and if containing $77.78 \%$ oils, the surfactant concentration must $\geq 5.5$ part of water. These microemulsions remained stable during storage at room temperature, even after centrifugation, but did not tolerate at high temperature. The maximum solubility of ascorbic acid in w/o microemulsion was $1 \%$. Ascorbic acid microemulsion resistant to photo-oxidation and effective inhibits that reaction in VCO. This study confirmed that w/o microemulsion can act as ascorbic acid delivery system to disperse into VCO for inhibiting its' quality deterioration due to photo-oxidation.
\end{abstract}

Keywords: inhibitory effect, ascorbic acid microemulsion, photo-oxidation, virgin coconut oil.

\section{INTRODUCTION}

Virgin coconut oil (VCO), unlike the coconut oil obtained from dried copra, is extracted directly from coconut meat under mild temperature. This extraction process provided the nutrition stability and its beneficial components. However, during prolonged storage or display at retailers VCO may undergo quality deterioration leading to rejection by consumers especially due to the presence of rancid flavor and odor.

Hydrolysis and oxidation are two main reactions which could result in the deterioration of oils. However, oxidation is mostly responsible for much more of the deterioration of fats and oils than hydrolysis (List et al., 2005). Oxidation reaction influences the chemical, sensory and nutritional properties of edible oils and thus plays an important role in determining their use and shelf-life (Anwar et al., 2007). Ultimately, this oxidative deterioration could lead to significant losses for producers, retailers, and consumers.
In my previous study, I found that within the period before the expiration date, 11 out of 18 commercial brands of VCO marketed by retailers around Yogyakarta-Indonesia fell short of the quality standards. The verification indicated that it's initiated by singlet oxygen oxidation or known as photo-oxidation. These oxidation products catalyze the oxidation chain reaction, resulting in the oils' quality deterioration.

The undesirable photo-oxidation reaction can be reduced by singlet oxygen quencher (SOQ). According to Lee et al. (1997), tocopherols, carotenoids, and ascorbic acid can be used for the practical reduction of singlet oxygen oxidation of oils and other oil-soluble components. However, the singlet oxygenquenching abilities of tocopherols are not effective as carotenoids whereas carotenoids generally get in colored, so unsuitable for VCO. Bowry and Stocker (1993) in Yamamoto (2001) reported that $\alpha$-tocopherol, the most effective of

\footnotetext{
${ }^{1}$ Department of Food Technology and Nutrition Faculty of Agricultural Technology, Widya Mataram University, Yogyakarta

$\triangle$ ambar_rukmini@yahoo.co.uk
} 
tocopherols derivatives, requires ascorbic acid as co-antioxidant.

L-Ascorbic acid or Vitamin C is a colorless, strong and powerful water-soluble antioxidant that efficiently protects important organic and biological molecules against oxidative degradation. It works even better in conjunction with other antioxidant, such as tocopherols and carotenoids by establishing a peculiar recycling system with a synergic effect (Nostro, 1997). However, due to its very poor solubility in nonaqueous media, ascorbic acid cannot be used to protect hydrophobic systems such as VCO. In this study, w/o microemulsion was used for facilitating ascorbic acid dispersion into the VCO toward quality deterioration due to photooxidation.

The microemulsion is defined as a system of water, oil and amphiphile which is a single optically isotropic and thermodynamically stable liquid solution (Danielsson and Lindman, 1981 in Pakpayat et al., 2009). Because of its several advantages such as transparent, thermodynamically stable (long self-life), low viscosity, easy formulation (low interfacial tension and almost spontaneous formation) and high surface area (high solubilisation capacity), its considered suitable for applying in VCO. The objectives of this study were to obtain the stable w/o microemulsion formula; to determine the solubility of ascorbic acid in w/o microemulsion, and the stability of ascorbic acid microemulsion against photo-oxidation; and to evaluate the inhibitory effect of ascorbic acid microemulsion toward photo-oxidation of VCO.

\section{MATERIALS AND METHODS}

A freshly prepared $\mathrm{VCO}$ obtained from a local VCO producer was filtered in the presence of anhydrous $\mathrm{Na}_{2} \mathrm{SO}_{4}$ to obtain the dry $\mathrm{VCO}$ and then used in this study as continuous phase. Low HLB surfactant, i.e. sorbitan monooleate (Span 80) and medium HLB surfactant, i.e. sorbitan monolaurate (Span 20) were purchased from Sigma Chemical Company (St. Louis, MO), and high HLB surfactant, i.e. polyoxyethylene sorbitan monolaurate (Tween 20) was purchased from Merck (Darmstadt, Germany). Deionized water was purchased from Brataco Chemika as disperse phase. Ascorbic acid was purchased from Sigma Chemical Company (St. Louis, MO) and all chemicals used were of analytical grade.

\section{Formulation of w/o microemulsion:}

\section{Determination of suitable HLB number for w/o microemulsion:}

Generally, w/o microemulsion can be formed with surfactants having low HLB value, range 3-8 (Flanagan and Singh, 2006). In this study, the microemulsion systems were prepared with ternary surfactants mixture consisted of Span 80, Span 20 and Tween 20 at various HLB numbers, i.e. $6,6.5,7,7.5$, and 8. Briefly, mixtures of deionized water with a combination of ternary surfactants at various HLB numbers on the ratio $1: 4(\mathrm{w} / \mathrm{w})$ and mixing by hot-plate stirrer (SRS 710 HA, Advantec, Japan) at medium speed. The temperature was kept at $40 \pm 2^{\circ} \mathrm{C}$. After 10 minutes, dry VCO was added by using a $50 \mathrm{~mL}$ burette and stirring at high speed. The microemulsion system was identified as clear and transparent solutions, obtained based on visual inspection.

\section{Determination of water/surfactant/oil ratio:}

Based on the selected of HLB number of surfactant mixtures, the ratio of water/surfactant/oil was determined. According to the same method as defined before, the microemulsion was prepared by mixing water and combination of surfactants and then titrated with dry VCO. The transparent solution obtained from the mixtures revealed the optimum ratio of water/surfactant/oil to prepare microemulsion. These optimum formulas were used for further experiments. The microemulsion samples were allowed to equilibrate at room temperature $\left(30 \pm 1^{\circ} \mathrm{C}\right)$ for at least 24 hours before they were examined to be transparent and homogeneous.

\section{Stability test of w/o microemulsion:}

According to Cho et al. (2008), the stability of microemulsions was examined during storage at room temperature and under extreme conditions. All prepared microemulsions (10 g) were stored in disposable conical tubes. 
Microemulsions stability was routinely monitored, initially by visual inspection of the samples on a daily and later by turbidity measurements monthly for 2 months at room temperature $\left(30 \pm 1^{\circ} \mathrm{C}\right)$.

The stability test under extreme condition conducted for a thermal stress test, and a centrifugation stress test. For a thermal stress test, $10 \mathrm{~g}$ microemulsions were subjected to mild until high temperature $\left(60-105^{\circ} \mathrm{C}\right)$ for up to 5 hours in a drying oven (MOV-112, Sanyo, Japan). For a centrifugation stress test, $10 \mathrm{~g}$ microemulsions were centrifuged at $5000 \mathrm{rpm}$ for 15 minutes in a centrifuge (EBA $3 \mathrm{~S}$ Hettich, Germany). After a thermal stress test or a centrifugation stress test, the microemulsion was monitored by visual inspection, and turbidity measurement using a UV/Vis spectrophotometer (UV-1650 PC, Shimadzu, Japan). Samples were contained within quartz cuvettes with a path length of $1 \mathrm{~cm}$ and all measurements were observed at a wavelength of $502 \mathrm{~nm}$. The turbidity was calculated as turbidity $\mathrm{x}$ path length $=2.303 \mathrm{x}$ absorbance (Fletcher and Morris, 1995 in Cho et al., 2008).

\section{Solubility of ascorbic acid in w/o microemulsion:}

For preparing of ascorbic acid microemulsion, the following procedure was employed: the desired amount of ascorbic acid was first dissolved in deionized water. The aqueous phase containing ascorbic acid was subsequently added with the right amounts (per weight) of surfactant mixtures and then stirring at medium speed for up to 10 minutes at $40 \pm 2^{\circ} \mathrm{C}$. After that, the dry VCO was titrated to those mixtures at high speed stirring for up to 10 minutes. The solubilisation limit of the ascorbic acid in w/o microemulsion was defined as the transition appearance from transparent to cloudy.

\section{Photo-oxidative stability of microemulsion:}

To evaluate the stability of microemulsion against photo-oxidation, a portion of w/o microemulsion or ascorbic acid microemulsion were placed in transparent serum bottles with rubber caps. Photo-oxidation was performed under accelerated condition using fluorescent lights with intensity of approximately 4000 lux and samples were exposed to that light for up to 5 hours at room temperature $\left(30 \pm 1^{\circ} \mathrm{C}\right)$. Peroxide values (PVs) of the samples were measured according to the method proposed by the AOCS Official Method (AOCS, 2004).

\section{Effect of ascorbic acid microemulsion on photo-oxidized VCO:}

To evaluate the inhibitory effect of ascorbic acid microemulsion on VCO against photooxidation, two set of samples were used. A portion of VCO samples containing $0,1,5$, or $10 \% \mathrm{w} / \mathrm{w}$ microemulsions were placed in a number of transparent serum bottles with rubber caps, while another portion was protected from light by wrapping the serum bottles with aluminum foil. Photo-oxidation was performed under accelerated condition using fluorescent lights with intensity of approximately 4000 lux and samples were exposed to that light for up to 8 hours at room temperature $\left(30 \pm 1^{\circ} \mathrm{C}\right)$. $\mathrm{PVs}$ and $p$ anisidine values $(p-\mathrm{AnVs})$ of the samples were measured at 1 hour interval. PVs and $p$-AnVs were determined according to the method proposed by the AOCS Official Method (AOCS, 2004). PV and $p$-AnV were used to calculate the total oxidation (TOTOX) of the samples. According to AOCS (2004), the use of PV and $p$ $\mathrm{AnV}$ analysis together gives a more complete picture of total oxidation than each test separately. The equation is TOTOX $=2 \mathrm{PV}+p-\mathrm{AnV}$. The low TOTOX values indicate good stability.

\section{Statistical analysis:}

Data from all investigations in each experiment were represented as the mean value of 3 replicates. Significant differences $(P<0.05)$ between means were determined using Duncan's multiple range tests.

\section{RESULTS AND DISCUSSION}

\section{A. Formulation of w/o microemulsion:}

\section{A.1. Suitable HLB number for w/o microemulsion:}

According to Fanun (2009), before preparing the microemulsions, the candidate ingredients should be established. Choosing a surfactant mixture with proper HLB is among 
necessary conditions for microemulsion formation. The value of the HLB number indicates how the surfactant will behave in a solution (Pilemand, 2002). The HLB is one of the most common methods to correlate surfactant structure with their effectiveness as emulsifiers. It is closely related to the capability of solubilisation the solubilised substances (Kruglyakov, 2000). According to Flanagan and Singh (2006), the surfactant, also called emulsifier or amphiphilic compound, plays an important role in microemulsion formation by reducing the interfacial tension which is facilitating the microemulsion formation.

Moreover, the chemical type of surfactant which best matches that of the oil must be chose, because the chain length compatibility of a surfactant and oil is important factor in the formation of microemulsion (Bayrak and Iscan, 2005 in Cho et al., 2008; Fanun, 2009). The combinations of high and low HLB value of surfactant provide the necessary conditions for the formation of a stable w/o microemulsion (Osborne et al., 1988 in Constantinides and Scalart, 1997; Pilemand, 2002; Garti et al., 2005; Li et al., 2005; Cho et al., 2008). The mix surfactants can also increase the solubility of the bioactive compound in the microemulsion (Flanagan and Singh, 2006). Because of the reasons, the water-in-VCO microemulsion in this experiment prepared by using the combination of Span $80(\mathrm{HLB}=4.3)$, Span $20(\mathrm{HLB}=8.6)$, and Tween $20(\mathrm{HLB}=$ 16.7).

In this experiment, it found that w/o microemulsion formed only at the HLB number of 7 which composed of $16.6 \%$ of Tween $20,15.0 \%$ of Span 20, and $68.4 \%$ of Span 80 . This result indicated that the HLB number of 7 with that combination of surfactants was the required for formatting water-in-VCO microemulsion. The transparent appearance at that HLB revealed the equilibrium condition of water/surfactants/VCO system. So, this HLB number was selected for further experiments.

\section{A.2. Optimum formula of w/o microemulsion:}

The microemulsion system may form at specific proportions of water, surfactants, and oil.
In this experiment, to determine the optimum formula of water-in-VCO microemulsion formulation, the combinations of water/surfactants/VCO at varied ratios (as shown at Table 1) were prepared. On dilution of solution having different water/surfactants ratios with VCO, a one-phase transparent solution was formed when the ratio of the mix of water/surfactants : VCO was $1: 3$ (or $75 \%$ of the oil phase) at the surfactants ratio $\geq 4.5$ part of water or $1: 3.5$ (or $77.78 \%$ of the oil phase) at the surfactants ratio $\geq 5.5$ part of water.

Table 1. Evaluation of water-in-VCO microemulsion formulation

\begin{tabular}{|c|c|c|c|}
\hline Formula & $\begin{array}{c}\text { Ratio of } \\
\text { water/surfactants }\end{array}$ & $\begin{array}{l}\text { Ratio of } \\
\text { (w/s) : } \\
\text { VCO }\end{array}$ & Appearance \\
\hline 1 & $1: 1.5$ & $1: 03$ & Cloudy \\
\hline 2 & $1: 02$ & $1: 03$ & $\begin{array}{l}\text { Cloudy, } \\
\text { separate } \\
\text { phase }\end{array}$ \\
\hline 3 & $1: 03$ & $1: 03$ & $\begin{array}{l}\text { Cloudy, } \\
\text { separate } \\
\text { phase }\end{array}$ \\
\hline 4 & 1:04 & $1: 03$ & Cloudy \\
\hline 5 & $1: 4.5$ & $1: 03$ & Transparent \\
\hline 6 & $1: 05$ & $1: 03$ & Transparent \\
\hline 7 & $1: 5.5$ & $1: 03$ & Transparent \\
\hline 8 & $1: 06$ & $1: 03$ & Transparent \\
\hline 9 & $1: 4.5$ & $1: 3.5$ & Cloudy \\
\hline 10 & $1: 05$ & $1: 3.5$ & $\begin{array}{l}\text { Slightly } \\
\text { cloudy }\end{array}$ \\
\hline 11 & $1: 5.5$ & $1: 3.5$ & Transparent \\
\hline 12 & 1:06 & $1: 3.5$ & Transparent \\
\hline 13 & $1: 04$ & $1: 04$ & $\begin{array}{l}\text { Slightly } \\
\text { cloudy }\end{array}$ \\
\hline 14 & $1: 05$ & 1:04 & $\begin{array}{l}\text { Slightly } \\
\text { cloudy }\end{array}$ \\
\hline 15 & $1: 06$ & $1: 04$ & $\begin{array}{l}\text { Slightly } \\
\text { cloudy }\end{array}$ \\
\hline
\end{tabular}

The formula of $1,2,3$, and 4 , could not form microemulsion system because of insufficient surfactants in the systems. According to Patel et al. (2007), the concentration of surfactants must be high enough to provide the 
number of surfactant molecules needed to stabilized the microdroplets to be produced by an ultra low interfacial tension $\left(<10^{-3} \mathrm{mN} / \mathrm{m}\right)$. It was very important things to promote the formation of microemulsion system which having diameter of the droplets in the range of 10-100 $\mathrm{nm}$.

In comparison between formula 5 , and 6 with the formula of $9,10,13,14$, and 15 , as amount of the oils phase increase, the system needs more surfactants to facilitate the formation of microemulsion. Economically, the usage of higher amount of surfactants was inefficient treatment. It also could increase the additive content in the products which was applied into microemulsion system. Consequently, the transparent systems obtained from the formula of $5,6,7,8,11$, and 12 were used for further experiment and named as formula A, B, C, D, E, and $F$.

\section{B. Stability of w/o microemulsion:}

\begin{tabular}{cccccc}
\multicolumn{5}{c}{ Table 2. Stability of water-in-VCO microemulsion using ternary nonionic surfactant } \\
\cline { 2 - 6 } Formula & \multicolumn{5}{c}{ Turbidity Index (\%) $^{*}$} \\
\cline { 2 - 6 } & Untreated & $\begin{array}{c}\text { After } \\
\text { centrifugation }^{\mathrm{c}}\end{array}$ & $\begin{array}{c}\text { After heating at } \\
60^{\circ} \mathrm{C}\end{array}$ & $\begin{array}{c}\text { After 1 month } \\
\text { storage }\end{array}$ & $\begin{array}{c}\text { After 2 months } \\
\text { storage }\end{array}$ \\
\hline A & $-0.094 \pm 0.006^{\mathrm{b}}$ & $-0.037 \pm 0.008^{\mathrm{c}}$ & $-0.166 \pm 0.004^{\mathrm{a}}$ & $0.065 \pm 0.002^{\mathrm{d}}$ & $0.138 \pm 0.002^{\mathrm{e}}$ \\
B & $-0.115 \pm 0.007^{\mathrm{b}}$ & $-0.053 \pm 0.006^{\mathrm{c}}$ & $-0.161 \pm 0.004^{\mathrm{a}}$ & $0.081 \pm 0.008^{\mathrm{d}}$ & $0.094 \pm 0.008^{\mathrm{e}}$ \\
C & $-0.092 \pm 0.008^{\mathrm{b}}$ & $-0.009 \pm 0.004^{\mathrm{c}}$ & $-0.177 \pm 0.006^{\mathrm{a}}$ & $0.071 \pm 0.006^{\mathrm{d}}$ & $0.136 \pm 0.004^{\mathrm{e}}$ \\
D & $-0.072 \pm 0.004^{\mathrm{b}}$ & $-0.041 \pm 0.006^{\mathrm{c}}$ & $-0.078 \pm 0.008^{\mathrm{a}}$ & $0.088 \pm 0.006^{\mathrm{d}}$ & $0.097 \pm 0.006^{\mathrm{e}}$ \\
E & $-0.064 \pm 0.002^{\mathrm{b}}$ & $-0.051 \pm 0.004^{\mathrm{c}}$ & $-0.136 \pm 0.002^{\mathrm{a}}$ & $0.074 \pm 0.006^{\mathrm{d}}$ & $0.081 \pm 0.006^{\mathrm{e}}$ \\
F & $-0.053 \pm 0.002^{\mathrm{b}}$ & $-0.044 \pm 0.006^{\mathrm{c}}$ & $-0.154 \pm 0.004^{\mathrm{a}}$ & $0.055 \pm 0.006^{\mathrm{d}}$ & $0.085 \pm 0.002^{\mathrm{e}}$ \\
\hline
\end{tabular}

Note: *): average of three replicates

The different letters followed the results indicate significant difference $(\mathrm{P}<0.05)$

Table 2 shows that the turbidity decreased after heating and slightly increased after centrifugation, and greatly increased after 1 month storage at room temperature. In this experiment, the heating test was performed under mild to high temperature $\left(60-105^{\circ} \mathrm{C}\right)$ for up to 5 hours and the centrifugation test was conducted at $5000 \mathrm{rpm}$ for 15 minutes. The negative values of turbidity index indicated that the samples have clearer appearance incomparable with the reference (VCO).

At mild temperature $\left(60^{\circ} \mathrm{C}\right)$ all of the microemulsions remained stable; they were still transparent after heating, even clearer incomparable with the untreated samples.
The stability of microemulsion is improved if a combination of surfactants is used because solubilisation reaches the maximum and the smallest particles are formed when the HLB of surfactant is optimum in a given oil-water system (Pilemand, 2002). The stability of microemulsion was evaluated by storing at room temperature and under accelerated (extreme) condition.

Accelerated testing methods are required for evaluating of long-term stability. This has been attempted by means of storage at elevated temperature and centrifugation (Morais et al., 2006 in Cho et al., 2008). It was observed by turbidity measurements. The turbidity of a sample is proportional to the average particle diameter (Cho et al., 2008). Hence, changes in the turbidity of a microemulsion sample can be used to derive changes in the particle volume resulting from either clustering or growth of the microemulsion droplets, and to obtain information on stability changes. The turbidity changes from this experiment were showed in Table 2.
However, they were intolerable to relatively high temperature $\left(70^{\circ} \mathrm{C}\right.$, and above) indicating with the separate phase. The separation phase may be due to the changes in nonionic surfactants structure which are likely to occur. Nonionic surfactants in particular are affected by changes in temperature, which affect their head-group size, thereby indirectly affecting their ability to solubilize oil (Sottmann and Strey, 1997 in Flanagan et al., 2006). Because of the reason, the structure of surfactant changed at $\geq 70^{\circ} \mathrm{C}$, affected the separation of microemulsion system. This study indicated that the water-in-VCO microemulsions 
suitable apply to the mild temperature processing products.

According to Li et al. (2005), as opposed to the single surfactant, combined use of surfactants might have provided better surfactants' HLB. As a result, it enhanced the flexibility of surfactant layer that was formed; it also enhanced the surfactants' ability to partition at higher levels into the water-oil interface; both of which stabilized microemulsion system. It was the reason for stabilizing the water-in-VCO microemulsion during storage, even after centrifugation or heating at mild temperature. Although there were significant differences $(\mathrm{p}<$ 0.05 ) on the turbidity index, all of samples had transparent appearance. According to Cho et al. (2008), the microemulsion which indicated a transparent liquid showed a turbidity value of less than $1 \%$. Thus, all of microemulsion formulas in this study could be declared as stable microemulsions and suitable for further applications.

\section{Solubility of ascorbic acid in w/o microemulsion:}

To determine the solubility of ascorbic acid in the w/o microemulsion, the ascorbic acid at different levels $(10,5,4,3,2,1,0.75$, and $0.5 \%$ $\mathrm{w} / \mathrm{w})$ was loaded. That resulting mixtures were evaluated with regard to their appearance. The results indicated that the incorporation of ascorbic acid at the level more than $1 \%(\mathrm{w} / \mathrm{w})$ obtained slightly turbid or cloudy solution with precipitations of ascorbic acid.

According to Pakpayat et al. (2009), incorporation of ascorbic acid in the formulated microemulsion leads to the microemulsion structure destabilization and do not allow to obtain transparent isotropic systems what about the protocol envisaged. Therefore, the ascorbic

Table 3. Photo-oxidative stability of microemulsion exposed to fluorescent light (4000 lux) for up to 5 hours

\begin{tabular}{llcccccc}
\hline \multirow{2}{*}{ Treatment } & \multicolumn{6}{c}{ PV $\left.(\mathrm{meq} / \mathrm{kg})^{*}\right)$} \\
\cline { 2 - 7 } & \multirow{2}{*}{ VCO } & \multicolumn{6}{c}{ water-in-VCO microemulsion formula } \\
\cline { 2 - 7 } & & $\mathrm{A}$ & $\mathrm{B}$ & $\mathrm{C}$ & $\mathrm{D}$ & $\mathrm{E}$ & $\mathrm{F}$ \\
\hline Untreated & $0.126^{\mathrm{c}}$ & $0.091^{\mathrm{a}}$ & $0.094^{\mathrm{a}}$ & $0.091^{\mathrm{a}}$ & $0.096^{\mathrm{a}}$ & $0.113^{\mathrm{b}}$ & $0.105^{\mathrm{b}}$ \\
Exposed to light & $1.714^{\mathrm{e}}$ & $1.261^{\mathrm{c}}$ & $1.296^{\mathrm{c}}$ & $1.285^{\mathrm{c}}$ & $1.299^{\mathrm{c}}$ & $1.317^{\mathrm{d}}$ & $1.333^{\mathrm{d}}$ \\
\hline
\end{tabular}

Note: *): average of three replicates

The different letters followed the results indicate significant difference $(\mathrm{P}<0.05)$

Table 3 shows that the light exposed VCO

or the water-in-VCO microemulsion had acid microemulsion areas were displacement to the lipophilic region. Because of the reason, reformulations of microemulsion had done with adding the oil phase (VCO) at the amount of ascorbic acid loaded. However, those formulas also did not produce transparent solution. Thus, the ascorbic acid microemulsion prepared by subtracting the amount of ascorbic acid from the aqueous phase (deionized water). These formulations allowed obtaining transparent solution at the concentration of ascorbic acid 1\% or less. The maximum solubilisation of ascorbic acid in w/o microemulsion formula $\mathrm{A}, \mathrm{B}, \mathrm{C}$, and $0.75 \%$. Those formulas showed that the maximum ability of w/o microemulsion to retain (or solubilize) the ascorbic acid without phase separation. These formulas then applied in further experiments.

\section{Photo-oxidative stability of microemulsion:}

The photo-oxidative stability of microemulsion was performed under accelerated condition using fluorescent lights with intensity of approximately 4000 lux and samples were exposed to that light for up to 5 hours at room temperature $\left(30 \pm 1^{\circ} \mathrm{C}\right)$. Photo-oxidation is a reaction that initiates quality deterioration in fatty product. Intense light exposure in photo-oxidation induces an increased rate of peroxide formation in the oil (Rahmani and Csallany, 1998). PV is a measure of the concentration of peroxides and hydro-peroxide forms in the initial stage of lipid oxidation. The number of peroxides reflects its oxidative level and thus its tendency to become rancid (Anwar et al., 2007; Kim et al., 2007; Marina et al., 2009). The PVs changes in the microemulsion exposed to fluorescent light were showed in Table 3. $\mathrm{D}$ was $1 \%$, whereas in formula $\mathrm{E}$, and $\mathrm{F}$ was 
significantly $(\mathrm{p}<0.05)$ higher $\mathrm{PV}$ than that's untreated samples. However, the microemulsions showed significantly $(p<0.05)$ lower PV than the original VCO samples. In this experiment, the microemulsions contained $75 \%$ of dry VCO (in

formula $\mathrm{A}, \mathrm{B}, \mathrm{C}$, and $\mathrm{D}$ ) or $77.78 \%$ (in formula $\mathrm{E}$, and F). My previous study indicated that light exposure with relatively high intensity (4000 lux) was very effective to initiate photo-oxidation in VCO. Consequently, increasing VCO in the light exposed microemulsion system could result in increasing PV. However, if the microemulsion was loaded with ascorbic acid, the PVs became zero at all of the treatment (data not shown).

These results indicated that ascorbic acid which was incorporated in the water-in-VCO microemulsion system could play as SOQ and inhibit the photo-oxidation reaction. As reported by Bodannes and Chan (1979), ascorbate can scavenge singlet oxygen, superoxide and peroxide. In comparison with the said study, this experiment resulted in a similar trend which was indicated with the zero values of PV in ascorbic acid microemulsions, even after exposed to the fluorescent light. This result indicated that the ascorbic acid microemulsion resistant to the photo-oxidation reaction.

\section{E. Effect of ascorbic acid microemulsion on photo-oxidized VCO:}

The effect of ascorbic acid microemulsion on photo-oxidized VCO was evaluated by measuring the PVs, $p$-AnVs, and TOTOX values of light exposed VCO containing microemulsion formula $\mathrm{A}$ at different concentrations $(0,1,5$, and $10 \% \mathrm{w} / \mathrm{w})$. The results were showed below.

\section{E.1. Peroxide value changes}

Figure 1 shows that the PV changes in the light exposed VCO containing w/o microemulsion without (Figure 1A) or with ascorbic acid loaded (Figure 1B). According to Rahmani and Csallany (1998), intense light exposure in photo-oxidation induces an increased rate of peroxide formation in the oil. In comparison with the said study, this experiment resulted in a similar trend.

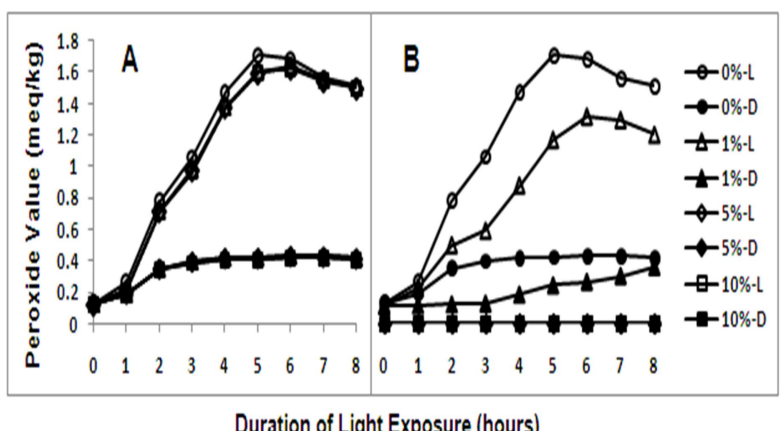

Figure 1. Peroxide value in VCO containing w/o microemulsion (A) or ascorbic acid microemulsion (B) exposed to fluorescent light for up to 8 hours. [(L) Light exposed samples; (D) light protected samples].

Figure 1A shows that the light exposed VCO containing different amount of w/o microemulsion showed very significantly $(\mathrm{p}<0.01)$ higher PV than that's the light protected samples but there was no significant different $(p>0.05)$ among the concentrations of $w / 0$ microemulsion addition. It's indicated that w/o microemulsion system did not affect on the photooxidized VCO.

Figure 1B shows that the significant effect of ascorbic acid microemulsion on photo-oxidized VCO. The ascorbic acid microemulsions were very significantly $(\mathrm{p}<0.01)$ lower the $\mathrm{PVs}$ of VCO. Even it could eliminate the PVs at the concentration of ascorbic acid microemulsion was $5 \%$ or $10 \%$. The high polarity of lipid hydroperoxide that produced during illumination would cause them to diffuse towards the waterVCO interface. The ascorbic acid in the microdroplets of microemulsion quenched those free radical hydroperoxides and made them no more detected as peroxides. Moreover, the ascorbic acid also could act as SOQ which was inhibiting the photo-oxidation and suppressing the peroxides formation.

As reported by Wanasundara and Shahidi (2005), ascorbic acid is effective in trapping singlet oxygen, superoxide, and peroxide. Mosca et al. (2008) also reported that the vitamin $\mathrm{C}$ in water-in-olive oil emulsion succeeds in acting as an effective antioxidant even if it is confined into water droplets, out of the reaction side of photooxidized olive oils. This result indicated that the ascorbic acid which was hydrophilic antioxidant, 
if incorporated into the microemulsion system was effective to protect the oils from photo-oxidation reactions.

Figure 1 also shows that the PVs decreased after 5 hours of fluorescent light exposure in light exposed VCO samples without or with $1 \%(\mathrm{w} / \mathrm{w})$ ascorbic acid microemulsion. In this condition, hydro-peroxides will have decomposed into secondary oxidation products. If the rate of hydroperoxide decomposition is greater than that of hydro-peroxide formation in the oil, it could have very low hydro-peroxide content. Because of the reason, it was considered to determine the secondary oxidation products.

\section{E.2. p-Anisidine value changes}

The $p$-AnV method measures the content of aldehydes (principally

2-alkenals and 2,4-alkadienals) generated during the decomposition of hydroperoxides. A higher level of $p-A n V$ revealed a higher extent of the secondary oxidation products formatting in light exposed oils which might be due, in part, to the enhanced rate of oxidative deterioration (Khan and Shahidi, 2002 in Anwar et al. 2007). The pAnVs in light exposed VCO samples containing microemulsion were showed in Figure 2.

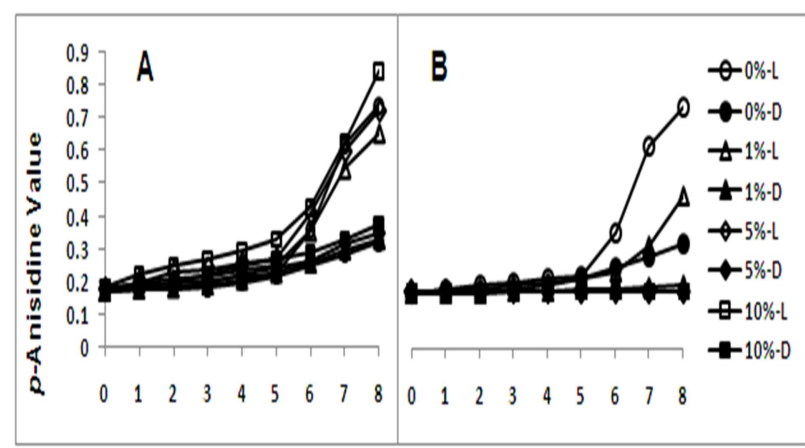

Duration of Light Exposure (hours)

Figure 2. $p$-Anisidine value in VCO containing w/o microemulsion (A) or ascorbic acid microemulsion (B) exposed to fluorescent light for up to 8 hours. [(L) Light exposed samples; (D) light protected samples].

Figure 2 shows that no significant different $(\mathrm{p}>0.05)$ in $p$-AnVs until 5 hours illumination of VCO samples containing w/o microemulsion (Figure 2A) or ascorbic acid microemulsion (Figure 2B). This result indicated the lag stage for formatting the secondary oxidation product. Along with this period, the light exposed VCO samples producing hydroperoxides. According to Osborn and Akoh (2004), the hydroperoxides must first be present before they can decompose into the secondary oxidation products. However, in the light exposed VCO containing w/o microemulsion or $1 \%(\mathrm{w} / \mathrm{w})$ ascorbic acid microemulsion significantly $(\mathrm{p}<0.05)$ increased the $p$-AnV after 5 hours illumination. It was indicated that intense light exposure in VCO leads the accumulation of secondary oxidation products which was increasing the $p$-AnVs.

Figure 2 also shows that significantly $(\mathrm{p}<0.05)$ lower $\mathrm{p}-\mathrm{AnVs}$ in the light protected samples and in the VCO containing ascorbic acid microemulsion. The $p-\mathrm{AnV}$ in the samples containing ascorbic acid microemulsion at concentration of 5 , or $10 \%(\mathrm{w} / \mathrm{w})$ had constant value during illumination. It was indicated that the ascorbic acid microemulsion effective to retard the photo-oxidation reaction and prevent the formation of hydroperoxides which decomposed to secondary oxidation products.

\section{E.3. TOTOX value changes}

The TOTOX value is a measure of the total oxidation, including primary and secondary oxidation products. It was expressed as $2 \mathrm{PV}+p$ $\mathrm{AnV}$. The $\mathrm{PV}$ and $p-\mathrm{AnV}$ reflect the oxidation level at early and later stages of oxidation reaction, respectively. During lipid oxidation, it is often observed that PV first rises, and then falls as hydroperoxides decompose. TOTOX value measures both hydroperoxides and their breakdown products, and provides a better estimation of the progressive oxidative deterioration of fats and oils (Shahidi and Zhong, 2005). The TOTOX values of light exposed VCO samples were showed in Figure 3.

Figure 3 had a similar trend with the Figure 1. At the 5 hours of the first stage illumination, light exposed VCO containing different amount of w/o microemulsion showed very significantly $(p<0.01)$ higher TOTOX value than that's the light protected samples but there was no significant different $(\mathrm{p}>0.05)$ among the concentrations of w/o microemulsion addition. 
After 5 hours illumination, there was constant of TOTOX value. It was indicated that the oxidation rate of light exposed VCO samples decreased after 5 hours illumination.

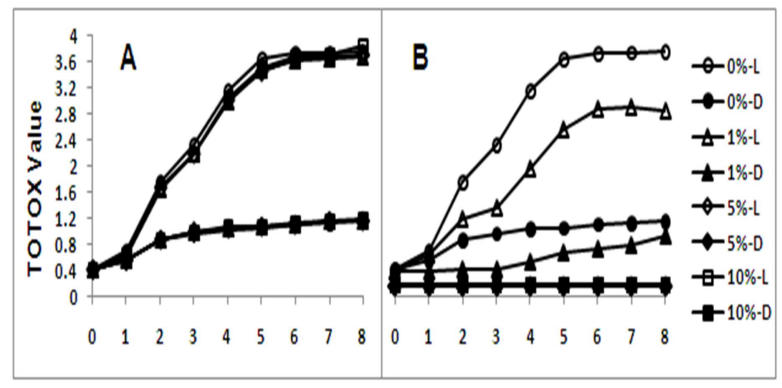

Duration of Light Exposure (hours)

Figure 3. TOTOX value in VCO containing w/o microemulsion (A) or ascorbic acid microemulsion (B) exposed to fluorescent light for up to 8 hours. [(L) Light exposed samples; (D) light protected samples].

Figure $3 \mathrm{~B}$ shows that the light exposed

VCO containing ascorbic acid microemulsion showed significantly $(\mathrm{p}<0.05)$ lower TOTOX value than that's the light exposed VCO without ascorbic acid microemulsion. It was indicated that the ascorbic acid microemulsion effective inhibit the photo-oxidation reaction in VCO.

\section{CONCLUSIONS}

Water-in-VCO (w/o) microemulsion could be formed on the HLB number of 7 . If this microemulsion containing $75 \%$ oils its need surfactant concentrations of $\geq 4.5$ part of water, and if containing $77.78 \%$ oils, the surfactant concentration must $\geq 5.5$ part of water. These microemulsions remained stable during storage at room temperature, even after centrifugation, but did not tolerate at high temperature. The maximum solubility of ascorbic acid in w/o microemulsion was $1 \%$. Ascorbic acid microemulsion resistant to photo-oxidation and effective inhibits that reaction in VCO which could affect to its quality deterioration.

\section{ACKNOWLEDGEMENT}

This work was financially supported by the Research Grant of Dissertation for the Doctorate Degree in 2010 from the Directorate General of Higher Education, the Ministry of National Education of the Republic Indonesia and author greatly appreciated the support.

\section{REFERENCES}

Anwar F, Chatha SAS dan Hussain AI. 2007. Assessment of oxidative deterioration of soybean oil at ambient and sunlight storage. Grasas Y Aceites 58(4):390-395.

AOCS. 2004. Official Methods and Recommended Practices of the AOCS, Fifth edition. American Oil Chemists' Society, Champaign, Illinois.

Bodannes RS dan Chan PC. 1979. Ascorbic acid as a scavenger of oxygen singlet. Febs Letters 105(2):195-196.

Cho YH, Kim S, Bae EK, Mok CK dan Park J. 2008. Formulation of a cosurfactant-free $\mathrm{o} / \mathrm{w}$ microemulsion using nonionic surfactant mixtures. Journal of Food Science 73(3):E115-E121.

Constantinides PP dan Scalart JP. 1997. Formulation and physical characterization of water-in-oil microemulsions containing long- versus medium-chain glycerides. International Journal of Pharmacology 158:57-68.

Fanun M. 2009. Microemulsions : Properties and Applications. CRC Press, New York.

Flanagan J dan Singh H. 2006. Microemulsion : a potensial delivery system for bioactives in food. Critical Review of Food Science and Nutrition 46:221-237.

Flanagan J, Kortegaard K, Pinder DN, Rades T dan Singh H. 2006. Solubilisation of soybean oil in microemulsions using various surfactants. Food Hydrocolloids 20:253-260

Garti N, Spernath A, Aserin A dan Lutz R. 2005. Nano-sized self-assemblies of nonionic surfactants as solubilization reservoirs and microreactors for food systems. Soft Matter 1:206-218. 
Kim HJ, Hahm TS dan Min DB. 2007. Hydroperoxide as a prooxidant in the oxidative stability of soybean oil. Journal of the American Oil Chemists' Society 84(3):349-355.

Kruglyakov PM. 2000. Hydrophile-Lipophile Balance of Surfactants and Solid Particles: Physicochemical Aspects and Applications, First edition. Elsevier Science B.V,.Amsterdam, Netherlands.

Lee KH,. Jung MY dan Kim SY. 1997. Quenching mechanism and kinetics of ascorbyl palmitate for the reduction of the photosensitized oxidation of oils. Journal of the American Oil Chemists' Society 74(9):1053-1057.

Li P, Ghosh A, Wagner RF, Krill S, Joshi YM dan Serajuddin ATM. 2005. Effect of combined use of nonionic surfactant on formation of oil-in-water microemulsions. International Journal of Pharmacology 288:27-34.

List GR, Wang T dan Shukla VKS. 2005. Storage, Handling and Tarnsport of Oils and Fats dalam Bailey's Industrial Oil and Fat Products, $6^{\text {th }}$ ed., vol. 5. John Wiley \& Sons, Inc., Hoboken, New Jersey.

Marina AM, Man YBC and Nazimah SAH (2009) Chemical Properties of Virgin Coconut Oil. Journal of the American Oil Chemists' Society 86:301-307.

Mosca M, Ceglie A dan Ambrosone L. 2008. Antioxidant dispersions in emulsified olive oils. Food Research International 41:201207.

Nostro PL. 1997. Supramolecular Aggregates from Vitamin C Derivatives: Structure and Properties. http://www.netscijournal.com/97v4/ 97014/index.htm [23 May 2009]
Osborn HT and Akoh CC. 2004. Effect of Emulsifier Type, Droplet Size, and Oil Concentration on Lipid Oxidation in Structured Lipid-Based Oil-in-Water Emulsion. Food Chemistry 84:451-456.

Pakpayat N, Nielloud F, Fortune R, TournePeteilh C, Villarreal A, Grillo I dan Bataille B. 2009. Formulation of ascorbic acid microemulsions with alkyl polyglycosides. European Journal of Pharmacology $72: 444-452$.

Patel MR, Patel RB, Parikh JR, Bhatt KK dan Kundawala AJ. 2007. Microemulsion : as novel drug delivery vehicle. Lates Reviews vol. 5 issue 6 (http://www.pharmainfo.net).

Pilemand C. 2002. Surfactants : Their Abilities and Important Physico-Chemical Properties. Arbejdsmiljøinstituttet, København.

Rahmani M and Csallany AS (1998) Role of Minor Constituents in the Photo-oxidation of Virgin Olive Oil. Journal of the American Oil Chemists' Society 75(7):837843

Shahidi F and Zhong Y. 2005. Lipid Oxidation: Measurement Methods in Bailey's Industrial Oil and Fat Products, $6^{\text {th }}$ ed., vol.5. John Wiley \& Sons, Inc., Hoboken, New Jersey.

Wanasundara PKJPD and Shahidi F. 2005. Antioxidants: Science, Technology, and Applications in Bailey's Industrial Oil and Fat Products, $6^{\text {th }}$ ed., vol.5. John Wiley \& Sons, Inc., Hoboken, New Jersey.

Yamamoto Y. 2001. Role of active oxygen species and antioxidants in photoaging. Journal of Dermatological Science 27(1):S1-S4. 